\title{
Comparing New-Generation Candidate Vaccines against Human Orthopoxvirus Infections
}

\author{
R. A. Maksyutov ${ }^{1 *}$, S. N. Yakubitskyi ${ }^{1}$, I. V. Kolosova1 , S. N. Shchelkunov ${ }^{1,2 *}$ \\ 'State Research Center of Virology and Biotechnology «Vector», Koltsovo, Novosibirsk region, \\ 630559, Russia \\ ${ }^{2}$ Institute of Cytology and Genetics, Siberian Branch of Russian Academy of Sciences, Novosibirsk, \\ 630090, Russia \\ E-mail: maksrinat@yandex.ru; snshchel@rambler.ru \\ Received: July 05, 2016; in final form January 23, 2017 \\ Copyright $\odot 2017$ Park-media, Ltd. This is an open access article distributed under the Creative Commons Attribution License, which permits \\ unrestricted use, distribution, and reproduction in any medium, provided the original work is properly cited.
}

\begin{abstract}
The lack of immunity to the variola virus in the population, increasingly more frequent cases of human orthopoxvirus infection, and increased risk of the use of the variola virus (VARV) as a bioterrorism agent call for the development of modern, safe vaccines against orthopoxvirus infections. We previously developed a polyvalent DNA vaccine based on five VARV antigens and an attenuated variant of the vaccinia virus (VACV) with targeted deletion of six genes (VAC $\Delta 6$ ). Independent experiments demonstrated that triple immunization with a DNA vaccine and double immunization with VACA6 provide protection to mice against a lethal dose $\left(10 \mathrm{LD}_{50}\right)$ of the ectromelia virus (ECTV), which is highly pathogenic for mice. The present work was aimed at comparing the immunity to smallpox generated by various immunization protocols using the DNA vaccine and VAC $\Delta 6$. It has been established that immunization of mice with a polyvalent DNA vaccine, followed by boosting with recombinant VAC $\Delta 6$, as well as double immunization with VAC $\Delta 6$, induces production of VACV-neutralizing antibodies and provides protection to mice against a $150 \mathrm{LD}_{50}$ dose of ECTV. The proposed immunization protocols can be used to develop safe vaccination strategies against smallpox and other human orthopoxvirus infections.
\end{abstract}

KEYWORDS DNA vaccine, vaccinia virus, virulence genes, protective potential, smallpox.

ABBREVIATIONS CPXV - cowpox virus, $\mathbf{E C T V}$ - ectromelia virus, LD $_{50}-50 \%$ lethal dose, $\mathbf{L I V P}-\mathbf{L}$-IPV vaccinia virus strain, MPXV - monkeypox virus, PCR - polymerase chain reaction, PFU - plaque forming unit, VACV vaccinia virus, VARV - variola virus.

\section{INTRODUCTION}

The Orthopoxvirus genus of the Poxviridae family includes human-pathogenic species, such as the variola virus (VARV), monkeypox virus (MPXV), cowpox virus (CPXV), and vaccinia virus (VACV). Mass vaccination with a conventional VACV-based vaccine protects not only from VARV, but also from the closely related MPXV and CPXV [1]. After 1980, the share of the population sensitive to VARV and other orthopoxviruses pathogenic to humans has constantly increased due to the eradication of smallpox and cessation of widespread immunization against the disease. This is evidenced in the increasingly more frequent multiple cases of orthopoxvirus infections in humans caused by such viruses as MPXV, CPXV, and VACV [2-6]. Moreover, VARV is considered a potential agent of bioterrorist attacks, which could have catastrophic consequences for the entire world population [6]. The lack of effective antiviral drugs and the risk associated with con- ventional VACV-based live vaccines, because of severe postvaccinal complications, necessitate the development of modern, safe orthopoxvirus vaccines and protocols for their use [7, 8].

Earlier, we developed a recombinant variant VAC $\Delta 6$ with targeted knockdown of six genes, encoding hemagglutinin $(A 56 R)$, the gamma-interferon-binding protein $(B 8 R)$, thymidine kinase $(J 2 R)$, the complementfixing protein $(C 3 L)$, the Bcl2-like apoptosis inhibitor (N1L), and the A35R gene, which controls antigen presentation by the class II major histocompatibility complex (MNSII), based on the LIVP VACV strain used in the Russian Federation for the vaccination of humans. It has been shown that inactivation of selected virulence genes does not affect the reproductive properties of VACV in mammalian cell cultures. The VAC $\Delta 6$ strain is significantly less reactogenic and neurovirulent and more immunogenic compared to the parent LIVP strain. Double subcutaneous injection of recom- 
binant variant VAC $\Delta 6$ induces significantly higher levels of virus-neutralizing antibodies in mice than the parental LIVP strain and provides complete protection to mice against the highly pathogenic ectromelia virus (ECTV), as opposed to the effect of the LIVP strain in this model, which is approved as a smallpox vaccine $[9$, 10].

Earlier, we implemented another independent approach to vaccinal prevention of smallpox. We developed a polyvalent DNA vaccine based on a mixture of recombinant plasmids containing the genes of five virion proteins of the VARV: A30, F8, M1, which are constituents of the surface membrane of intracellular virions, and A36, B7, which are located on the membrane of the extracellular form of the virus, under the control of the CIVV promoter. Triple intradermal immunization with a polyvalent DNA vaccine induced the production of virus-neutralizing antibodies and provided complete protection to mice against ECTV infection at a dose of $10 \mathrm{LD}_{50}[11-13]$.

Along with the development of fundamentally new vaccines, a combination of various types of vaccines which can complement each other and induce strong and broad immunity is another promising avenue in improving the efficacy of smallpox vaccination [14]. Such a heterologous immunization strategy (primeboost), where the subunit vaccine (DNA vaccine) is used to prime the immune system and where the attenuated variant of VACV is used for subsequent booster vaccination, is considered promising.

This study compared immunity against smallpox induced by double immunization with various combinations of polyvalent DNA vaccines and a highly attenuated VAC $\Delta 6$ strain.

\section{EXPERIMENTAL}

Bacteria, viruses, cell cultures

In this study, we used Escherichia coli XL2-blue, the VAC $\Delta 6$ strain [10], the LIVP VACV strain (derived from a Lister strain obtained from the Institute of Viral Preparations, Moscow), and a K-1 ECTV strain from the collection of SRC VB "Vector," continuous cell culture 4647 of African green monkey kidney cells [15] from the collection of cell cultures of SRC VB "Vector" cultivated on a DMEM medium supplemented with $10 \%$ fetal bovine serum.

Polyvalent DNA vaccine

A set of recombinant plasmids based on the vector plasmid pcDNA3.1, bearing genes of five VARV antigens, including A30, F8, M1 antigens of the surface membrane of intracellular virions and A36, B7 antigens of the membrane of extracellular forms of the virus under the control of a cytomegalovirus promoter, was obtained previously [11-13]. Preparative quantities of plasmid DNA were accumulated in E. coli cells and purified using the EndoFree Plasmid Giga Kit (Qiagen, USA) according to the manufacturer's recommendations. Plasmid DNA concentration was measured spectrophotometrically on a Ultrospec 3000 pro instrument (GE Healthcare Life Sciences, USA).

\section{Accumulation and purification of viruses}

A monolayer of 4647 cells grown in culture flasks with a growth surface of $175 \mathrm{~cm}^{2}$ (volume of $650 \mathrm{ml}$ ) was infected with VACV (VAC 6 or LIVP strain), and the multiplicity of infection was $1 \mathrm{PFU} /$ cell. The virus was incubated in a DMEM medium with $2 \%$ fetal bovine serum for 48 hours at $37^{\circ} \mathrm{C}$ until complete cytopathic effect, followed by the obtaining of a cryolysate (three freezing-thawing cycles) of the infected cells, and double or triple sonication of the latter in the $22 \mathrm{kHz} \mathrm{MSE}$ 500 disintegrator for $10-15$ seconds. Cell debris was removed by low-speed centrifugation (10 min at 4,000 g). The supernatant was centrifuged for 1.5 hours at 30,000 $g$. The precipitated virus was re-suspended in $4 \mathrm{ml}$ of saline. Infectious virus titer was determined using the agar-free plaque technique in a 4647 cell monolayer.

Study of the immunogenicity and protectivity In this study we used Balb/c mice (females, weight 14-16 g, 5-6 weeks old) from the mouse bank of the SRC VB "Vector." Mice were divided into groups of 10 animals. They were immunized with a polyvalent DNA vaccine subcutaneously and with a mixture of $\mathrm{pcD}-$ NA-A30, pcDNA-A36, pcDNA-M1, pcDNA-F8, and pcDNA-B7 plasmids (50 $\mu \mathrm{g}$ of each plasmid, a total dose of $250 \mu \mathrm{g} / 100 \mu \mathrm{l}$ per mouse) intradermally. The mice were immunized subcutaneously with VAC $\Delta 6$ or LIVP strain at a dose of $10^{7} \mathrm{PFU} / 100 \mu \mathrm{l}$ per mouse. Control group mice were injected with a volume equal to that of the saline that was used to prepare virus dilutions. Immunization was performed twice at an interval of 21 days as shown in Table 1.

Blood samples were collected from the retrobulbar venous plexus of pre-anesthetized mice 19 days after the second immunization, incubated at $4^{\circ} \mathrm{C}$ for 24 hours to form a fibrin clot, and centrifuged for $10 \mathrm{~min}$ at $5,000 \mathrm{~g}$. Serum preparations from one group of animals were then pooled and heated at $56^{\circ} \mathrm{C}$ for $30 \mathrm{~min}$. Titer of VACV-neutralizing antibodies was determined on a 4647 cell culture according to [16], using serial fivefold dilutions of sera, which were mixed with an LIVP strain of VACV at the working dilution of $50 \mathrm{PFU} /$ well. The effectiveness of the neutralization was calculated with respect to the number of plaques in the sera-free wells as -lg of the highest serum dilution, which provides $50 \%$ neutralization of VACV. 
The animals under mild ether anesthesia were subjected to intranasal inoculation with ECTV, which is highly pathogenic to mice, at a dose of $150 \mathrm{LD}_{50} / 20 \mu \mathrm{l}$ per mouse according to [17] 21 days after the second immunization. The mice were followed for 14 days, and the number of survived and dead mice was recorded.

\section{Data analysis}

The statistical significance of the experimental data was evaluated based on the Student's t-test using the Origin Professional 8.1.10.86 software. The differences were considered statistically significant at $P<0.05$ [18].

\section{RESULTS}

Preparative quantities of pre-engineered pcDNA-A30, pcDNA-A36, pcDNA-M1, pcDNA-F8, and pcDNA-B7 plasmids were accumulated in E. coli cells and purified using the EndoFree Plasmid Giga Kit (Qiagen, USA) according to the manufacturer's instructions, followed by confirmation of the accuracy of insertions by restriction analysis using AsuNHI and HindIII endonucleases (Fig. 1) and sequencing.

VAC $\Delta 6$ and LIVP vaccinia virus strains were produced in a 4647 cell culture recommended for the production of a smallpox vaccine [19] and purified according to the aforementioned method. The strains were identified using a PCR analysis based on the loci of six inactivated genes (Tab. 2, Fig. 2).

The immunogenicity of double immunization with various combinations (Tab. 1) of the polyvalent DNA vaccine and a highly attenuated strain VAC $\Delta 6$ was assessed based on the level of induced virus-neutralizing antibodies in the mice serum sampled 21 days after the second immunization. As can be seen from the data shown in Fig. 3, the combination of DNA \& VAC $\Delta 6$ vaccines induced the accumulation of VACV-neutralizing antibodies whose level was comparable to the level of antibodies induced by double vaccination with a parent-strain LIVP. Moreover, double immunization with a VAC $\Delta 6$ strain induced significantly higher levels of neutralizing antibodies, which is consistent with our previous results [10].

As shown in our previous studies, triple immunization with a polyvalent DNA vaccine or double immunization with the VAC $\Delta 6$ strain provides $100 \%$ protection to mice subsequently infected with ECTV at a dose of $10 \mathrm{LD}_{50} /$ mouse $[10,12]$. For this reason, a significantly higher resolving dose of ECTV was used, $150 \mathrm{LD}_{50} /$ mouse, in order to assess the differences in the effectiveness of the used immunization protocols. As a result, a partial protective effect of double immunization (DNA \& VAC $\Delta 6$, LIVP \& LIVP and VAC $\Delta 6 \&$ VAC $\Delta 6$ ) was observed in three test groups (Fig. 4.).

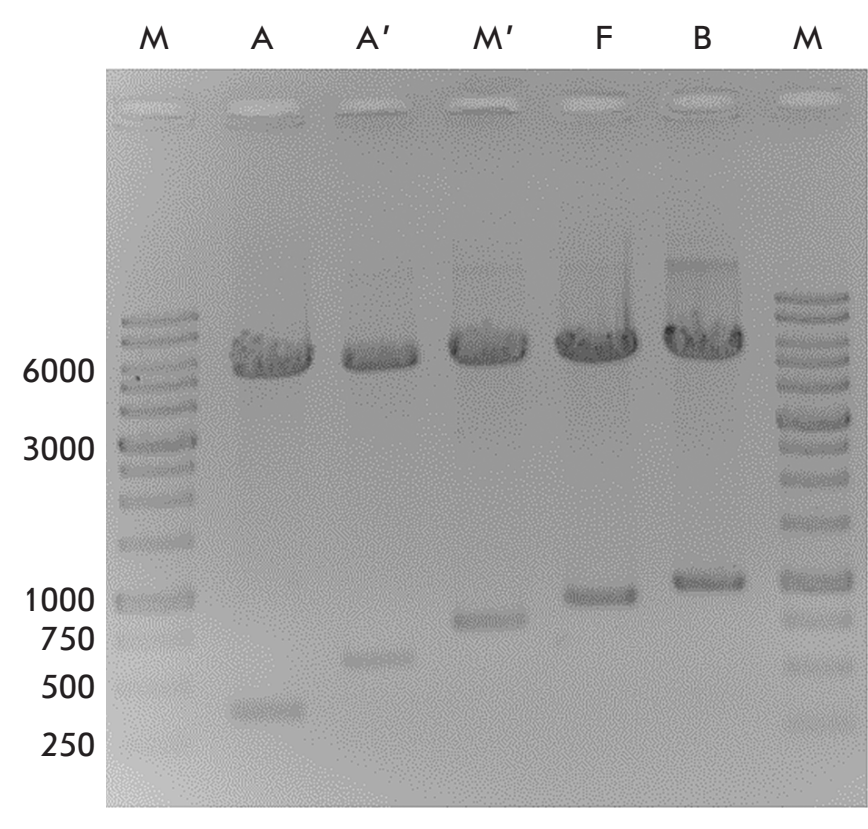

Fig. 1. Result of electrophoretic separation of DNA fragments produced after hydrolysis of the recombinant plasmid with the restriction endonucleases $\mathrm{AsuNHI}$ and Hindlll on a $1.2 \%$ agarose gel. $A, A^{\prime}, M^{\prime}, F, B-D N A$ fragments obtained for the recombinant plasmids pcDNAA30, pcDNA-A36, pcDNA-M1, pcDNA-F8, and pcDNA$B 7$, respectively. $M$ - DNA ladder, fragment length in bp is shown on the left

$$
\text { LIVP, } \quad \text { VAC } \triangle 6
$$

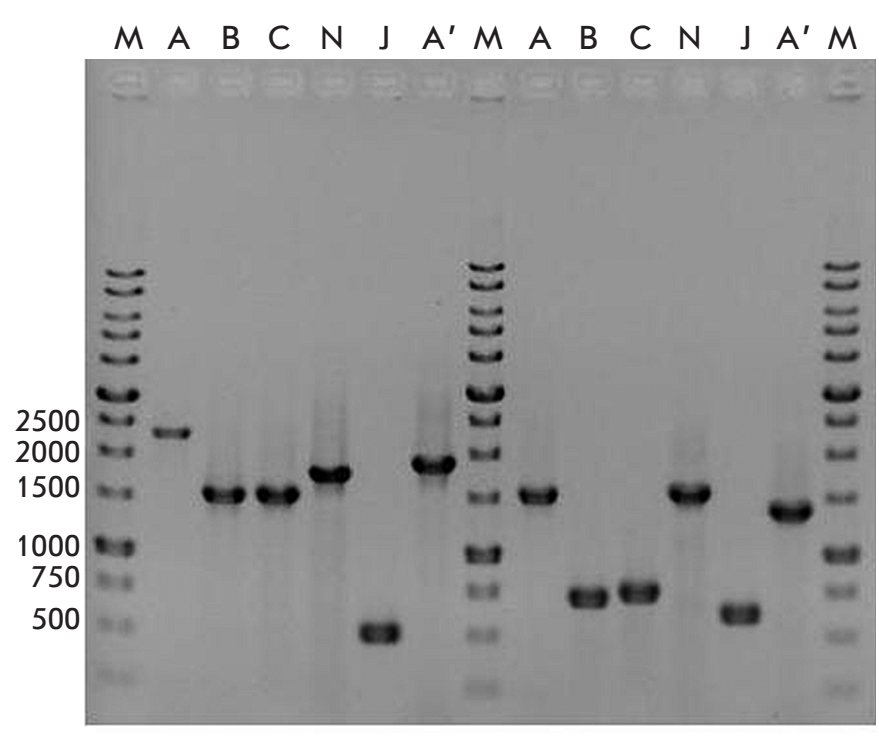

Fig. 2. Verification of deletions/insertions by PCR. PCR products formed from DNA of the parent clone VACV LIVP and VAC $\triangle 6$ with deletion of six virulence genes. A, $B, C, N, J, A^{\prime}-P C R$ products obtained with the appropriate primer pairs for the $A 56 R, B 8 R, C 3 L, N 1 L, J 2 R$, and $A 35 R$ genes. $M-D N A$ ladder, fragment length in bp is shown on the left 
Table 1. Testing scheme to assess the immunogenicity and protection of the vaccines in animal experiments

\begin{tabular}{|c|c|c|c|}
\hline \multirow{2}{*}{ Group } & \multicolumn{2}{|c|}{ Vaccine, dose per animal } & \multirow{2}{*}{$\begin{array}{l}\text { Protectivity test, } \\
\text { day } 42\end{array}$} \\
\hline & $\begin{array}{l}1^{\text {st }} \text { immunization, } \\
\text { day } 1\end{array}$ & $\begin{array}{l}2^{\text {nd }} \text { immunization, } \\
\text { day } 21\end{array}$ & \\
\hline DNA\&DNA & $\begin{array}{l}\text { DNA vaccine } \\
250 \mu \mathrm{g}\end{array}$ & $\begin{array}{l}\text { DNA vaccine } \\
250 \mu \mathrm{g}\end{array}$ & $\begin{array}{c}\text { K-1 strain of ECTV, } \\
150 \mathrm{LD}_{50}\end{array}$ \\
\hline DNA\&VAC $\Delta 6$ & $\begin{array}{l}\text { DNA vaccine } \\
250 \mu \mathrm{g}\end{array}$ & $\begin{array}{l}\text { VAC } \Delta 6 \text { strain } \\
10^{7} \mathrm{PFU}\end{array}$ & $\begin{array}{c}\text { K-1 strain of ECTV, } \\
150 \mathrm{LD}_{50}\end{array}$ \\
\hline VAC $\Delta 6 \& \mathrm{VAC} \Delta 6$ & $\begin{array}{l}\text { VAC } \Delta 6 \text { strain } \\
10^{7} \mathrm{PFU}\end{array}$ & $\begin{array}{l}\text { VAC } \Delta 6 \text { strain } \\
10^{7} \mathrm{PFU}\end{array}$ & $\begin{array}{c}\text { K-1 strain of ECTV, } \\
150 \mathrm{LD}_{50}\end{array}$ \\
\hline LIVP\&LIVP & $\begin{array}{c}\text { LIVP VACV strain } \\
10^{7} \mathrm{PFU}\end{array}$ & $\begin{array}{c}\text { LIVP VACV strain } \\
10^{7} \mathrm{PFU}\end{array}$ & $\begin{array}{c}\text { K-1 strain of ECTV, } \\
150 \mathrm{LD}_{50}\end{array}$ \\
\hline $\mathrm{K}-$ & Saline & Saline & $\begin{array}{c}\text { K-1 strain of ECTV, } \\
150 \mathrm{LD}_{50}\end{array}$ \\
\hline
\end{tabular}

Table 2. PCR analysis aimed at identification of the recombinant VACV

\begin{tabular}{|c|c|c|c|}
\hline Gene & Primer, nucleotide sequence $\left(5^{\prime} \rightarrow 3^{\prime}\right)$ & LIVP strain, bp & VAC $\Delta 6$ strain, bp \\
\hline A56R & $\begin{array}{l}\text { GTGGTATGGGACACCACAAATCCAA } \\
\text { ATTAAACATTCCTAGAATTAATCCCGCTC }\end{array}$ & 2366 & 1425 \\
\hline B8R & $\begin{array}{l}\text { TCACAAATATGATGGTGATGAGCGA } \\
\text { CGTGATATACCCTAGCCATAGGCAT }\end{array}$ & 1555 & 737 \\
\hline C3L & $\begin{array}{l}\text { TCGCGCTTTACATTCTCGAATCT } \\
\text { TGTTCGTGTGTTCTTGCGGTGA }\end{array}$ & 1542 & 751 \\
\hline N1L & $\begin{array}{c}\text { GGGTTGGATCCTTTACACATAGATCTACTACAGGCGGAACA } \\
\text { GGGAAAGCTTAATTTGTGAAGATGCCATGTACTACGCT }\end{array}$ & 1784 & 1431 \\
\hline $\mathrm{J} 2 \mathrm{R}$ & $\begin{array}{l}\text { ATATGTTCTTCATGCCTAAACGA } \\
\text { ATGAAGGAGCAAAAGGTTGTAAC }\end{array}$ & 512 & 617 \\
\hline A35R & $\begin{array}{l}\text { ACGACGGATGCTGAAGCGTGTTATA } \\
\text { AAACGATGTTACCAATCGTTTGCTAGGT }\end{array}$ & 1880 & 1360 \\
\hline
\end{tabular}

Maximum survival was observed in the VAC $\Delta 6 \& V A C \Delta 6$ group animals, who received double vaccination with $\mathrm{VAC} \Delta 6$, and in DNA \& VAC 66 group animals, wherein the immune system was primed using the polyvalent DNA vaccine, and attenuated VAC $\Delta 6$ was used for subsequent booster vaccination. All control-group animals died on the $8^{\text {th }}$ day, and all DNA \& DNA-group animals died on the $9^{\text {th }}$ day after infection with the ectromelia virus. The lack of complete protection can be explained by the use of extremely high doses of the ectromelia virus, which is heterologous to VACV.

\section{DISCUSSION}

Variolation, i.e. intradermal injection of infectious material from smallpox patients to healthy people, was the first method used to protect people from devastating epidemics of smallpox. The disease induced thus had a short incubation period and was relatively mild compared to conventional human-to-human respiratory transmission of the virus. The mortality caused by the inoculation was $0.5-2 \%$ as opposed to the $20-30 \%$ observed during variola virus epidemics [20]. Discovery of the possibility of human vaccination by inoculation with the cowpox virus and later with the vaccinia virus resulted in a significantly lower risk of severe adverse reactions. In the second half of the XXth century, when VACV was used for immunization, mortality was 1-25 per 1 million vaccinated people [21]. In the case of this vaccination, the risk group included primarily people with immunodeficiency, such as transplant patients, HIV-infected patients, individuals taking immunosuppressive drugs, and others. In this regard, modified vaccines with improved safety characteristics were developed based on VACV. For example, late in the XXth century, Russian researchers developed a live vaccine based on the recombinant strain LIVP VACV, which was tested on humans [22].

To date, there has been no mass vaccination against smallpox. However, there are categories of people who are at risk of becoming infected with smallpox or other 


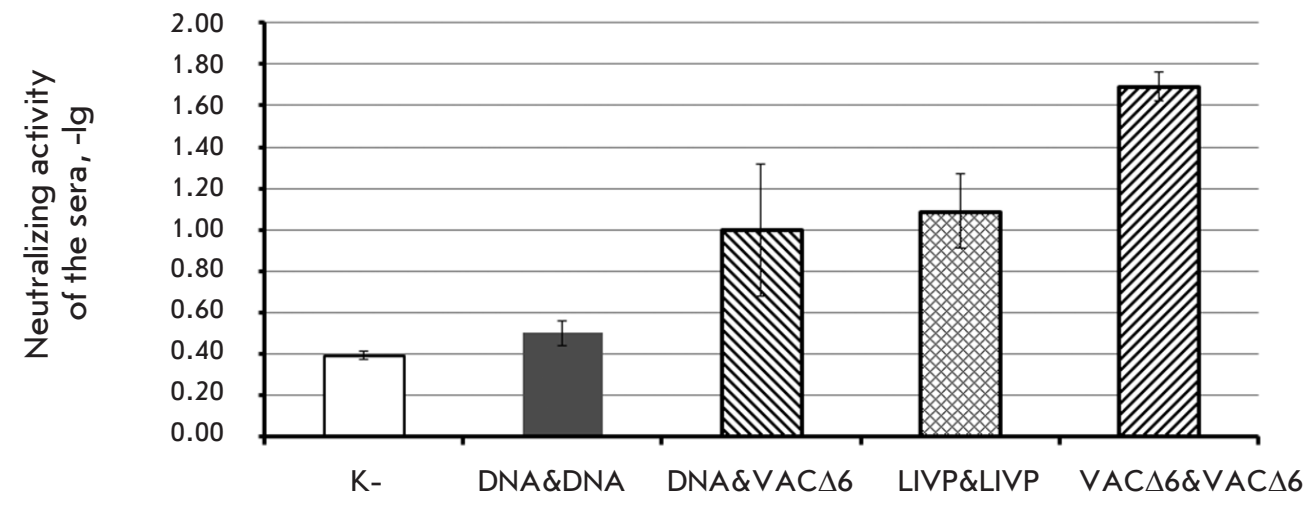

Fig. 3. The level of serumneutralizing activity against VACV, following double immunization with study preparations (DNA vaccine, VAC $\Delta 6$ and LIVP VACV strains) pathogenic orthopoxviruses based on their professional occupation. These categories comprise the risk group, and they should undergo obligatory vaccination against smallpox. First, this concerns personnel involved in epidemiological surveillance, the medical staff of infectious departments at hospitals, and employees of virology laboratories dealing with orthopoxviruses. In the case of smallpox outbreaks (e.g., as a result of a bioterrorist attack), all inhabitants of a region must be vaccinated. The conventional first-generation smallpox vaccine based on the LIVP strain, which is currently used for vaccination, has a lot of contraindications and can cause complications with varying severity. It is worth noting that it is somewhat difficult to demonstrate protective immunity against smallpox induced by vaccination of new preventive medication, since the smallpox has been eliminated, and it is impossible to test the efficacy of these vaccines against the natural disease in the absence of epidemics.

Previously, we implemented two independent approaches to the development of safe vaccines against human orthopoxvirus infections. We developed a highly attenuated variant of the vaccinia virus, $\mathrm{VAC} \Delta 6$, with targeted knockdown of six genes, and a polyvalent DNA vaccine based on five antigens of the variola vi- rus. Independent experiments demonstrated that triple immunization with a DNA vaccine and double immunization with $\mathrm{VAC} \Delta 6$ provide protection to mice against a lethal dose $\left(10 \mathrm{LD}_{50}\right)$ of the ectromelia virus, which is highly pathogenic to mice $[10,12]$.

In this study, we compared the immune response developed against orthopoxvirus using various immunization protocols with a DNA vaccine and VAC $\Delta 6$. The product of the $A 35 R$ gene, one of the six genes deleted in the recombinant variant VAC $\Delta 6$, reduces the antigen presentation by the class II major histocompatibility complex. Therefore, the VAC $\Delta 6$ strain induces a higher level of VACV-neutralizing antibodies than the parental clone LIVP, and it is more effective in protecting animals from ECTV infection at a dose of $150 \mathrm{LD}_{50}$. Combined immunization with a DNA vaccine and a recombinant $\mathrm{VAC} \Delta 6$ variant leads to a lower level of neutralizing antibodies compared to double immunization with $\mathrm{VAC} \Delta 6$. However, it provides the same level of protection. Apparently, this can be attributed to the fact that the DNA vaccine better induces the cell component of the immune response during primary immunization, which is also required for effective orthopoxvirus elimination from the organism $[23,24]$.

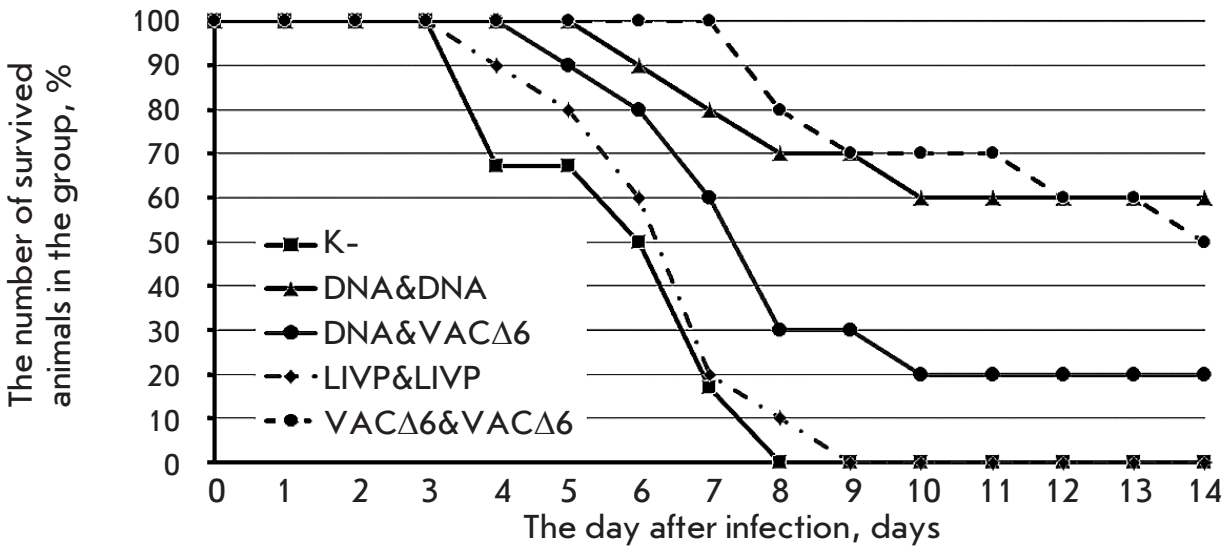

Fig. 4. Time-course of mortality after double immunization of mice with the preparations under study(DNA vaccine, VACD6 and LIVP VACV strains), followed by challenge with ECTV at a dose of 150 LD $_{50} /$ mouse 


\section{CONCLUSION}

In this study, we used a heterologous immunization strategy to enhance the effectiveness of smallpox vaccination, where the immune system was primed using a polyvalent DNA-vaccine based on five VARV genes, and an attenuated version VAC $\Delta 6$ was used for subsequent booster vaccination. The level of protection induced this way was the same as that in the option with double immunization using a VAC $\Delta 6$ strain and superior to that induced by double immunization with the LIVP VACV strain used in the Russian Federation for human vaccination. The proposed immunization protocols can be used to develop safe vaccination strategies against smallpox and other human orthopoxvirus infections. DNA vaccination, followed by vaccination

\section{REFERENCES}

1. Marennikova S.S., Shchelkunov S.N. Pathogenic for humans orthopoxviruses. M: KMK Scientific Press Ltd, 1998. $386 \mathrm{p}$.

2. Stephenson J. // J. Am. Med. Assoc. 2003. V. 290. P. 23-24.

3. Lewis-Jones S. // Curr. Opin. Infect. Dis. 2004. V. 17. P. 81-89.

4. Campe H., Zimmermann P., Glos K., Bayer M., Bergemann H., Dreweck C., Graf P., Weber B.K., Meyer H., Büttner M., et al. // Emerg. Infect. Dis. 2009. V. 15. P. 777-780.

5. Ninove L., Domart Y., Vervel C., Voinot C., Salez N., Raoult D., Meyer H., Capek I., Zandotti C., Charrel R.N. // Emerg. Infect. Dis. 2009. V. 15. P. 781-784.

6. Shchelkunov S.N. // PLoS Pathogens. 2013. V. 9. e1003756.

7. Shchelkunov S.N. // Vaccine. 2011. V. 29. Suppl. 4. P. D49D53.

8. Breman J.G., Henderson D.A. // N. Engl. J. Med. 2002. V. 346. P. 1300-1308.

9. Yakubitsky S.N., Kolosova I.V., Maksyutov R.A., Shchelkunov S.N. // Acta Naturae. 2015. V. 7. № 4. P. 113-121.

10. Yakubitsky S.N., Kolosova I.V., Maksyutov R.A., Shchelkunov S.N. // Dokl. Akad. Nauk. 2016. V. 466. P. 241-244.

11. Maksyutov R.A., Shchelkunov S.N. // Russ. J. Immunol. 2010. V. 4. P. 25-32.

12. Maksyutov R.A., Gavrilova E.V., Kochneva G.V., Shchelkunov S.N. // J. of Vaccines. 2013. http://dx.doi. org/10.1155/2013/618324. with live-attenuated virus VAC $\Delta 6$ can be considered as advantageous in terms of safety. It should be noted that the double vaccination protocol is not optimal for emergency prevention of smallpox. In this case, single-dose administration of the conventional smallpox vaccine based of the LIVP VACV strain is advisable.

This work was supported by the Federal Target Program National System of Chemical and Biological Safety (2009-2014), the Russian Foundation for

Basic Research (grant number 15-04-01326a), the

Russian Science Foundation (Project No 16-15-10101), and budgetary project of the Institute of Cytology and Genetics of the Siberian Branch of the Russian Academy of Sciences No 0324-2015-0004.

13. Maksyutov R.A., Shchelkunov S.N. // Mol. Gen. Mikrobiol. Virusol. 2011. V 2. P. 30-34.

14. Radosevic K., Rodriguez A., Lemckert A., Goudsmit J. // Expert Rev. Vaccines. 2009. V. 8. P. 577-592.

15. Mironova L.L., Hapichev Yu.H. Line heteroploid cell 4647: study, application, prospects. M., 1994. 146 p.

16. Leparc-Goffart I., Poirier B., Garin D., Tissier M.-H., Fuchs F., Crance J.-M. // J. Clin. Virol. 2005. V. 32. P. 47-52. 17. Martinez M.J., Bray M.P., Huggins J.W. // Arch. Pathol. Lab. Med. 2000. V. 124. P. 362-377.

18. Ashmarin I.P., Vorobiev A.A. Statistical methods in microbiological studies. L.: Gos. izd. med. lit., 1962.186 p. 19. Scarnovich M.O., Radaeva I.F., Vdovichenko G.V., Nechaeva E.A., Sergeev A.A., Petrishenko V.A., Plyasunov I.V., Shishkina L.N., Ternovoi V.A., Smetannikova M.A., et al. // Vopr. virusol. 2007. V. 2. P. 37-40.

20. Fenner F., Henderson D.A., Arita I., Jezek Z., Ladnyi I.D. Smallpox and Its Eradication. Geneva: World Health Organization, 1988. $1460 \mathrm{p}$.

21. Gurvich E.B. // Vaccine. 1992. V. 10. № 2. P. 96-97.

22. Chernos V.I., Chelyapin N.V., Antonova T.P., et al. // Vopr. virusol. 1990. V. 2. P. 132-135.

23. Kennedy J.S., Frey S.E., Yan L., Rothman A.L., Cruz J., Newman F.K., Orphin L., Belshe R.B., Ennis F.A. // J. Infect. Dis. 2004. V. 190. № 7. P. 1286-1294.

24. Ennis F.A., Cruz J., Demkowicz W.E., Rothman A.L., McClain D.J. // J. Infect. Dis. 2002. V. 185. № 11. P. 16571659 . 